\title{
New Aluminosilicate Materials with Hierarchical Porosity Generated by Aerosol Process
}

\author{
A. Chaumonnot ${ }^{1}$, F. Tihay' ${ }^{1}$ A. Coupé ${ }^{2}$, S. Pega ${ }^{2}$, C. Boissière ${ }^{2}$, D. Grosso ${ }^{2}$ and C. Sanchez ${ }^{2 *}$ \\ 1 Institut français du pétrole, IFP-Lyon, Rond point de l'échangeur de Solaize, BP 3, 69360 Solaize - France \\ 2 Laboratoire de Chimie de la Matière Condensée de Paris, CNRS UMR7574, Université Pierre et Marie Curie, Paris 6, 4 place Jussieu, \\ 75252 Paris Cedex 05 - France \\ e-mail: alexandra.chaumonnoł@ifp.fr - fanny.tihay@ifp.fr - aureliecoupe@hotmail.com - steph81_09@hotmail.com - cedric.boissiere@upmc.fr \\ david.grosso@upmc.fr - clement.sanchez@upmc.fr \\ * Corresponding author
}

\begin{abstract}
Résumé - Matériaux aluminosilicates innovants à porosité hiérarchisée obtenus par voie aérosol - Cet article met en évidence le fort potentiel d'un procédé d'atomisation (ou procédé aérosol) pour obtenir de nouvelles familles de solides aluminosilicates présentant une porosité hiérarchisée dans la gamme de la micro à la macroporosité. Il est ainsi possible d'obtenir, en une seule étape de synthèse, et grâce à un procédé fonctionnant en continu, des aluminosilicates mésostructurés à forte teneur en aluminium, des solides composites constitués de nanocristaux de zéolithe piégés dans une matrice mésostructurée et des aluminosilicates micro, méso et macroporeux présentant des propriétés catalytiques en craquage du cumène inédites. Ces résultats prometteurs ouvrent des perspectives intéressantes pour le développement de nouveaux supports acides pour des catalyseurs d'hydrocraquage.
\end{abstract}

\begin{abstract}
New Aluminosilicate Materials with Hierarchical Porosity Generated by Aerosol Process - This paper underlines the great advantage of using a spray-drying process (aerosol process) to synthesise new families of aluminosilicate materials with a hierarchical porosity from the microporous to the macroporous scales. In concrete terms, high aluminum content mesostructured solids, zeolite mesostructured aluminosilicate composites and amorphous hierarchical aluminosilicate solids with micro, meso and macroporosity have been successfully synthesised. Notice that the latter family is characterised by non usual acidic properties in cumene cracking catalytic reaction. Such results open then new perspectives in the development of innovating acidic catalysts for hydrocracking reactions.
\end{abstract}




\section{INTRODUCTION}

According to the International Energy Agency (IEA), the global demand in energy should increase by up to $53 \%$ between 2004 and 2030 [1]. This increase would be due especially to electricity and transportation fuel demand, where the key energetic resources are mostly oil based. In particular, the global diesel fuel production is constantly increasing in order to meet the transports energy requirements. In addition, crude oil reserves are decreasing and their exploitation becomes more and more difficult, pushing refiners to process heavier and lower quality feed stocks. Moreover, since the end of the 1970's, the increasing awareness of the need to protect the environment has deeply impacted the refining industry (harsher motor fuels specifications, waste limitations, etc.).

In this context, the conversion of heavy petroleum fractions into transportation fuels, and into diesel in particular, represents an important technological and economical challenge for refiners. Especially, the conversion of the specific Vacuum Gas Oil fraction (VGO) occurs mainly via Fluidized Catalytic Cracking (FCC) or Hydrocracking (HCK) processes which consist in the transformation of heavy petroleum feedstocks into lighter hydrocarbon. These processes are performed at high temperatures $\left(350-600^{\circ} \mathrm{C}\right)$, under atmospheric pressure (FCC) or high hydrogen pressure (HCK) [2]. The HCK process takes place in the presence of bifunctional solid catalysts characterised by a metallic function (hydro-dehydrogenation active sites) and an acidic function (cracking sites). The latter is held by an acidic solid support which usually belongs either to the amorphous mesoporous aluminosilicates family or to the crystalline microporous zeolites family. However, these supports are still not optimised to perfectly match the market trends. In fact, the narrow pore size of zeolites limits the diffusion of heavy molecules and the amorphous nature of the mesoporous aluminosilicate materials limits their activity due to their moderate acidity. Consequently, the use of a zeolite type solid as catalyst support provides good yields in gasoline whereas an amorphous aluminosilicate type solid leads preferentially to a good quality diesel but with a low conversion rate. To overcome the drawbacks of these two types of solids, a great challenge in the oxide engineering field would be to synthesise an alternative solid with large pores and high acidity which would allow to reach a high level of conversion and selectivity in diesel.

\section{MESOSTRUCTURED ALUMINOSILICATE MATERIALS: A POSSIBLE ALTERNATIVE TO CLASSICAL HCK SUPPORTS?}

The quest for alternative solids has already led to the discovery at the beginning of the 90's of a new class of materials: the mesostructured materials [3]. A mesostructured solid is characterised by an organised and uniform porosity at the mesoporous scale (pore diameter between 2 and $50 \mathrm{~nm}$ according to the IUPAC classification). The principle of the synthesis is derived from the sol-gel synthesis used to obtain zeolite materials, except that the usual molecular microporosity directing agent has been replaced by a supramolecular one (micelles of surfactant), generating periodic mesoporous voids. In fact, the presence of both organic surfactants and inorganic precursors in an aqueous or aqueous - alcoholic media leads to the development of favourable interactions between self-assembled organic micelles and inorganic walls in formation. This phenomenon takes place in specific conditions of reactants concentration, $\mathrm{pH}$ and temperature and leads to the formation of hybrid materials consisting in micellar mesophases (2D hexagonal, cubic, wormlike phases, etc.) embedded in an inorganic oxide matrix. Finally, the mesostructured solid is obtained by the removal of the surfactant by washing or calcination steps. The resulting mesostructure clearly depends on the geometry and the arrangement of the surfactant micelles generated by the amphiphilic molecule self-assembly process. Depending on the concentration $(c)$ of the organic surfactant, two synthesis pathways have been proposed. When $c \gg$ CMC (Critical Micelle Concentration: concentration of surfactant above which micelles are spontaneously formed) a micellar mesophase is initially formed. After hydrolysis and condensation of the inorganic precursors around this template, the resulting solid is characterised by an ordered porosity of geometry close to that of the initial templating organic mesophase. This pathway is called "True Liquid Crystal templating" (TLC) (Fig. la). When $c \approx \mathrm{CMC}$, the mesostructuration phenomenon occurs by a "cooperative self-assembly mechanism" between inorganic precursors and surfactant molecules or macromolecules. This means that the hydrolysis - condensation reactions of the inorganic species, the selfassembly of the surfactant and the development of non covalent attractive interactions between these two phases occur simultaneously (Fig. 1b).

The discovery of these new synthesis methods has led to many studies generating a wide range of oxide materials, especially silica based materials [4]. Most famous, MCM-41 [4] and SBA-15 [5] silicas are respectively obtained using a quaternary ammonium salt (e.g. cetyltrimethylammonium bromide, $\mathrm{CH}_{3}\left(\mathrm{CH}_{2}\right)_{15} \mathrm{~N}\left(\mathrm{CH}_{3}\right)_{3}{ }^{+} \mathrm{Br}^{-}$, CTAB) as molecular surfactant and a non ionic bloc copolymer such as Pluronics P123 as macromolecular surfactant $\left([\mathrm{EO}]_{20}-[\mathrm{PO}]_{70}-[\mathrm{EO}]_{20}\right.$, and F127: $[\mathrm{EO}]_{106}-[\mathrm{PO}]_{70}-[\mathrm{EO}]_{106}$, with EO: polyethylene oxide and PO: polypropylene oxide). The solids are characterised by high specific areas around 1000 and $600 \mathrm{~m}^{2} / \mathrm{g}$ respectively and a $2 \mathrm{D}$ hexagonal or $3 \mathrm{D}$ cubic mesostructure with pore diameters tuneable between 2 and $10 \mathrm{~nm}$. The positively charged quaternary ammonium salt induces a mesostructuration phenomenon into acidic or alkaline 




Figure 1

Main synthesis pathways to mesostructured materials. a) True Liquid Crystal templating. b) Cooperative self-assembly mechanism.

media due to the development of electrostatic interactions with positively or negatively charged oligomers or walls of silica. On the contrary, non ionic bloc copolymers interact with hydroxyl groups (potentially protonated) of the inorganic condensed species because of hydrogen bonding, generating the mesostructuration. Consequently, the associated syntheses are usually performed between close to neutral and acidic media.

As shown in the literature, the possible ways to obtain mesostructured silicas are manifold and depend on $\mathrm{pH}$, surfactants, temperature, etc. These methods could be tailored to the development of aluminosilicate mesostructured solids with the addition of an aluminum precursor in the initial solution [6]. The resulting solids develop textural and structural properties very similar to those of the equivalent silicas and moreover present acidic properties due to the aluminum incorporation into the silica matrix. It is usually admitted that the acidic properties of these mesostructured materials are very similar to those of mesoporous non-organised amorphous aluminosilicate materials [7]. However, because of their mesostructuration, they are less stable under thermal or hydrothermal conditions than non-organised aluminosilicate solids and zeolites. Consequently, most recent studies were focused on the development of mesostrutured aluminosilicate solids with improved acidity and hydrothermal resistance. In this aim, the most studied line of attack in the literature was to develop mesostructured aluminosilicate materials with zeolitic walls, also called "mixed zeolite-mesostructured solids". Two main approaches were assessed and are discussed below. The first one consists in aging solutions of reactants usually employed in zeolites synthesis at temperatures ranging from room temperature to $100^{\circ} \mathrm{C}$ [8]. These solutions are assumed to contain zeolite seeds, which are precursors of the zeolite crystallites growth. These zeolite seeds containing solutions are then added to a surfactant solution and the resulting gel is usually hydrothermally treated. Most of the obtained solids are amorphous mesostructured materials, meaning that the crystallisation of the walls into zeolite does not occur. However, theses materials seem to be more hydrothermally stable and more acidic than equivalent amorphous mesostructured solids obtained without zeolite seeds. The second approach, called Dry Gel Conversion (DGC), consists in the crystallisation of the walls of a previously synthesised amorphous mesostructured aluminosilicate solid in water or in an alkaline aqueous media (with amines) [9]. It has been postulated that this crystallisation proceeds by means of a dissolution - crystallisation phenomenon which leads to a progressive destruction of the mesostructured phase, promoting zeolite crystals growth. It is sometimes 


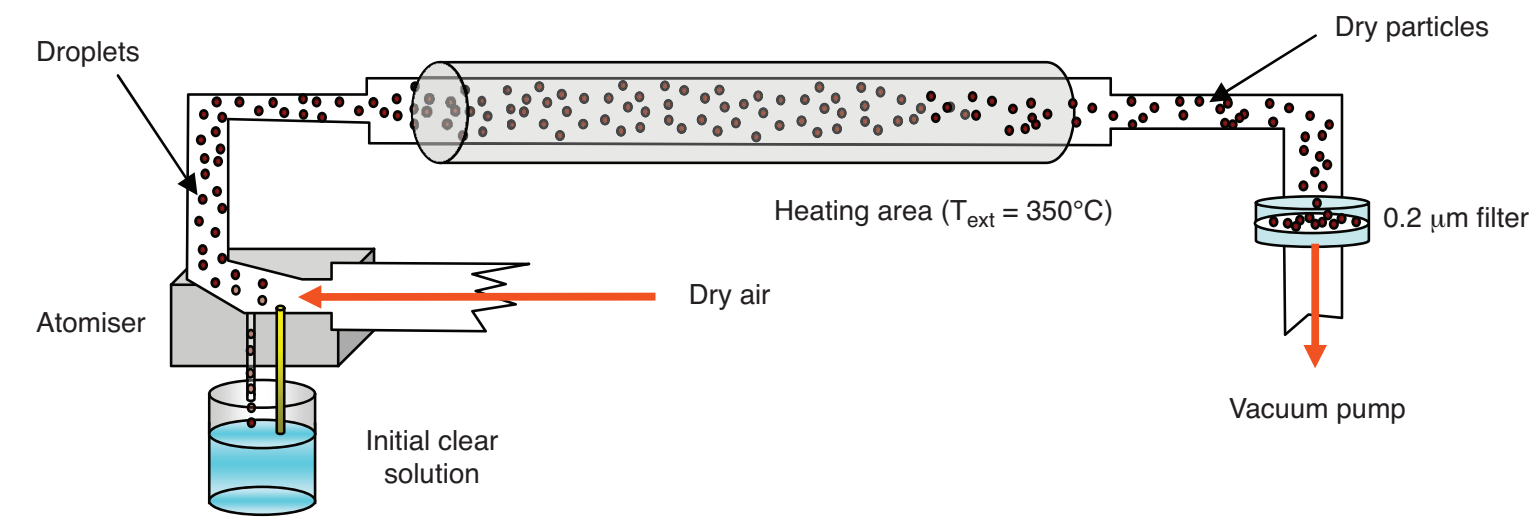

Figure 2

Spray-drying synthesis set-up.

mentioned that a perfect control of experimental conditions allows to achieve the synthesis of mesostructured solids with zeolite objects in the walls, but without long range organisation. These results are based on spectroscopic or catalytic data and should be taken with precaution.

To summarise, it can be considered that aluminosilicate mesostructured solids and especially "mixed zeolitemesostructured solids" are very promising acidic supports. However, despite the real interest of the scientific community in these solids, they are not yet used in industrial applications. The main reasons are of course the weakness of the acidic properties and the lack of hydrothermal resistance which still need to be increased, but also the preparation methods which are experimentally very demanding. In fact, the classical preparation process involves two main steps, precipitation and autoclaving, which are time consuming and for which operating parameters are rather difficult to control. During the last 10 years, other synthesis processes have been studied, especially processes involving Evaporation Induced Self-Assembly (EISA) [10-12]. However, to our knowledge, despite the very attractive potential of EISA to obtain mesostructured objects, this process has not yet been used to develop highly acidic aluminosilicate mesostructured solids.

In this article, we present several new families of aluminosilicate materials obtained by EISA using an aerosol process. The first part will be focused on the description of the aerosol technology and its advantages, and the following parts will underline the textural and structural properties of the new solids obtained.

\section{THE AEROSOL PROCESS: A VERY PROMISING SYNTHESIS METHOD TO DEVELOP NEW ALUMINOSILICATE MESOSTRUCTURED SOLIDS}

As mentioned previously, mesostructured solids are usually obtained by precipitation of inorganic precursors around organic templates in solution. The process is usually static and the system's evolution is governed by thermodynamics. The EISA concept consists in the progressive evaporation of a solution containing inorganic precursors and organic surfactants at a concentration that is initially lower than the CMC [13]. This evaporation leads to a progressive increase in the concentration of all the reactants which in turns induces the mesostructuration process. Consequently, this method clearly depends on the kinetics of solvent evaporation, of template structuration, of inorganic species condensation and on the technological strains due to the chosen evaporation process. Among the available evaporation processes, dip-, spin- or spray-coating [13] allow the synthesis of mesostructured oxide films whereas spray-drying performed via an aerosol process allows the synthesis of spherical elementary particles $[12,14]$. The spray-drying technique used in this study (schematically represented in Fig. 2) consists in the atomisation of the initial solution containing all the precursors by means of a vector gas under pressure. As-formed micron size droplets are transported to a heating area where the solvent evaporation induces, within each droplet, an increase in the concentration of non-volatile species, which leads, under suitable conditions, to the self-assembly of surfactant and to the condensation of hydrolysed inorganic precursors (and eventually to the formation of mesostructured particles). The obtained dry particles are finally collected onto a filter and then are dried and calcined.

Depending on experimental conditions, the kinetics of evaporation involved in EISA could also lead to another chemical phenomenon than mesotructuration which is called spinodal decomposition. This phenomenon induces the formation of interpenetrated organic and inorganic areas by phase separation in the dry hybrid particles collected at the end of the aerosol process. Consequently, the solids obtained are often mesoporous or even macroporous with a nonorganised porosity. Although these solids do not present the 
advantages of a periodic mesoporosity (they usually develop lower surface areas), their bicontinuous structure can be valuable for industrial applications because this texture is very suitable for reactants and products diffusion [15].

Compared to the precipitation method, the aerosol process presents many advantages. First, it is a continuous and fast process (droplet to dry particle in 1 to $4 \mathrm{~s}$ ). Second, scaling up of this process to industrial scale can be reasonably proposed. And finally, it allows the perfect control of the chemical composition of the final solid because any non volatile component present in the atomisable solution is still present in the final dry particles because of the EISA phenomenon. Furthermore, depending on the technological specifications of the equipment, the size distribution of the elementary particles can be controlled (monomodal distribution size could also be considered). Consequently, small particles of several nanometers could be obtained and then used to attenuate diffusion limitations.

In the literature, some authors have already taken advantage of the aerosol technique for the preparation of pure silica solids [13]. Nevertheless, as already mentioned, aluminosilicate mesostructured solids have barely been studied by means of this convenient process [16]. Therefore, the validation of this process as a new way to develop aluminosilicate materials has been studied. The resulting data are summarised in the next sections.

\section{EXPERIMENTAL SECTION}

Tetraethylorthosilicate and aluminum tri-sec-butoxide were used for all the samples prepared as siliceous and aluminum inorganic precursors. A solution (4\% in water) of tetrapropylammonium hydroxyde (TPAOH) was used for the series 5 samples.

Atomisation of solutions was performed by a 6-Jet 9306A atomiser from TSI with an air pressure of 8 Psi. The formed droplets were dried by passing through a quartz reactor heated at $350^{\circ} \mathrm{C}$. The obtained powders were treated at $90^{\circ} \mathrm{C}$ overnight and then calcined at $550^{\circ} \mathrm{C}$ for 8 hours.

Inorganic compositions of solids were controlled by ICP elemental analysis.

Low angles XRD patterns were recorded on a Philipps PW 1820 and on a D8 ADVANCE Bruker AXS for solids obtained by means of CTAB and copolymers as surfactants respectively. $\mathrm{N}_{2}$ adsorption-desorption isotherms were recorded at $77 \mathrm{~K}$ on a Micromeretics ASAP 2000 after pretreatment of samples under vacuum during $7 \mathrm{~h}$ at $150^{\circ} \mathrm{C}$. Surface area values were obtained by means of the BET model. Monomodal porosity at low $P / P_{0}$ values was calculated with the geometrical mathematic model $4 \times V / S_{\mathrm{BET}}$ with $V=$ mesoporous volume. Bimodal porosity at high $P / P_{0}$ values was calculated by means of the Broekhoff and De Boer method with the adsorption branch [17]. Bimodal porosity at low $P / P_{0}$ values was calculated by means of the Barret Joyner and Halenda method with the adsorption branch [18]. Micropores diameter was calculated by means of the $\alpha$-plot method using LiCHrospher Si-1000 silica as reference [19].

TEM pictures were recorded on a JEOL at $100 \mathrm{kV}$ by means of $70 \mathrm{~nm}$ microtomised samples.

3D-TEM technique involved a Tecnai 20F from FEI, operating at $200 \mathrm{kV}$, equipped with a high tilt holder, and an automated acquisition software. 3D-TEM quantitative information was the result of a binarisation of the volume after 3D filtering and automatic segmentation, followed by an extension to 3 dimensions of classical mathematical morphology calculation. The macroporous volume was estimated by counting the number of voxels (i.e. pixels in 3D) of the 3D object and by subtraction of the number of voxels of void. The specific surface area was obtained by counting the frontier voxels. For comparison with global physical measurements, a density of $1.2 \mathrm{~g} / \mathrm{mL}$ was used, which is the value for a classical microporous aluminosilicate solid.

All cumene cracking catalytic tests (leading to benzene and propene formation) were performed with a constant weight of sample. $50 \mathrm{mg}$ of sample powder were placed in a quartz reactor. Pre-treatment under nitrogen at $300^{\circ} \mathrm{C}$ during $15 \mathrm{~h}$ and then at $500^{\circ} \mathrm{C}$ during $2 \mathrm{~h}$ was performed. Cumene at a constant temperature of $14^{\circ} \mathrm{C}$ was evaporated using a $50 \mathrm{~mL} / \mathrm{min}$ nitrogen flux through the powder sample and the cracking reaction was performed at $300^{\circ} \mathrm{C}$. Final products were analysed by means of a Perichrom 2100 chromatograph. Conversion result was defined by the following ratio: $100 \times(\mathrm{mol}$ number of transformed cumene $) /($ mol number of initial cumene) and was expressed in \%. Results are expressed either at constant weight of solids or at constant surface area of solids normalised at $100 \mathrm{~m}^{2}$.

\section{AMORPHOUS MESOSTRUCTURED ALUMINOSILICATE SOLIDS OBTAINED BY THE AEROSOL PROCESS [8]}

A preliminary study of the formation in an acidic media of mesostructured pure silica particles by the aerosol process, followed by in situ SAXS, has shown that critical experimental parameters are the solvent composition (ratio water/alcohol), the temperature of the heating area and the concentration of the non-volatile species in the initial solution [12]. On the basis of these results, atomisable clear solutions with a wide range of $\mathrm{Si} / \mathrm{Al}$ molar ratios and with the following final molar composition have been prepared: $1,30,40,0.18$ or $0.01,0.02$ respectively in $\mathrm{Si}+\mathrm{Al}, \mathrm{EtOH}, \mathrm{H}_{2} \mathrm{O}, \mathrm{CTAB}$ or $\mathrm{P} 123, \mathrm{HCl}$. Either CTAB or P123 were used, resulting in two series of amorphous mesostructured aluminosilicate solids with a range of $\mathrm{Si} / \mathrm{Al}$ molar ratios between 1 and 10 (Tab. 1, $\mathrm{CTAB}=$ Series $1, \mathrm{P} 123=$ Series 2$)$. Notice that hydrolysis times $(t)$ of the initial solution before atomisation are $0.17 \mathrm{~h}$ 
(10 $\mathrm{min}$ ) and $18 \mathrm{~h}$ respectively for CTAB and bloc copolymer structuring agents. Samples were labelled C(P)- $X$ - $Y$ where $\mathrm{C}$ or P represents the CTAB or P123 surfactant, $X$ represents the $\mathrm{Si} / \mathrm{Al}$ molar ratio and $Y$ represents the hydrolysis time. Pure silica solid was also synthesised under the same experimental conditions (C-Si-0.17).

\section{TABLE 1}

Experimental $\mathrm{Si} / \mathrm{Al}$ molar ratios of solids obtained with $\mathrm{CTAB}, 1 \leq \mathrm{Si} / \mathrm{Al} \leq 10$ and $t=0.17 \mathrm{~h}$, series 1 and $\mathrm{P} 123$, $1 \leq \mathrm{Si} / \mathrm{Al} \leq 10$ and $t=18 \mathrm{~h}$, series 2

\begin{tabular}{c|c|c}
\hline & Samples & Molar Si/Al \\
\hline \multirow{4}{*}{ Series 1 } & C-Si-0.17 & $\infty$ \\
\cline { 2 - 3 } & C-9.3-0.17 & 9.5 \\
\cline { 2 - 3 } & C-4-0.17 & 4.3 \\
\cline { 2 - 3 } & C-1-0.17 & 1.3 \\
\hline \multirow{4}{*}{ Series 2 } & P-9.3-18 & 9.4 \\
\cline { 2 - 3 } & P-4-18 & 4.1 \\
\cline { 2 - 3 } & P-1-18 & 1 \\
\hline
\end{tabular}

The measured aluminum contents underline the remarkable control of the chemical composition of the solids obtained by means of the EISA process. Moreover, unusually high values of aluminum have been incorporated $(\mathrm{Si} / \mathrm{Al} \approx 1)$ compared with classical precipitation methods where $\mathrm{Si} / \mathrm{Al}$ molar ratio values under 10 are difficult to reach because of a partial dissolution of aluminum precursors in the initial solution which can not be incorporated in the final solid matrix [20].

In addition, each aluminosilicate material synthesised is characterised by a wormlike mesostructuration. This organised mesoporosity is attested by the correlation peak observed by low angles XRD. TEM pictures and low angles XRD analysis of each series of samples show that an increase in the aluminum content induces a progressive modification of the structuration leading to short range organisation of the inorganic matrix (Fig. 3 and 4 for series 1, Fig. 5 and 6 for series 2). This effect of the aluminum content, already known for equivalent solids obtained by precipitation [21], is obvious by looking at the transition between the well organised $2 \mathrm{D}$ hexagonal mesostructure of the pure silica sample C-Si-0.17 (Fig. $3 a$ ) and the disordered 2D hexagonal structure leading to wormlike structure of the aluminosilicate materials in series 1 (for example Fig. 3c). In addition, it is observed for the highest aluminum content sample of series 2 (P-1-18) that the loss of mesostructuration is almost complete.

Solids of series 1 and 2 are obviously different and their textural parameters depend on the nature of the surfactants used (molecular/macromolecular). Samples C-9.3-0.17 and C-4-0.17 present small mesopores with uniform size around $3 \mathrm{~nm}$ characterised by reversible $\mathrm{N}_{2}$ adsorption-desorption isotherms of type IVc. The isotherm of C-1-0.17 sample is similar except that a $\mathrm{H}_{2}$ type hysteresis cycle is also observed, resulting from the existence of additional mesopores, larger and less uniform in size (Fig. 7). Samples of series 2 are all characterised by $\mathrm{N}_{2}$ adsorption-desorption isotherms of type IV with hysteresis cycles stemming from calibrated and periodic mesoporosity around $8 \mathrm{~nm}$ (Fig. 8). For both series, the following general trend is observed: the progressive loss of mesostructuration induced by higher aluminum contents is accompanied by a decrease in surface area and pore volume values (Tab.2). Interestingly, we notice that all these samples are purely mesoporous, showing no microporosity.

Besides the nature of the organic surfactant and the aluminum content, the influence of hydrolysis time $(t)$ of the initial solution before atomisation has also been studied. Consequently, two additional series of samples, equivalent to series 1 and 2 but with hydrolysis times of $18 \mathrm{~h}$ (series 3 ) and $0.17 \mathrm{~h}$ (series 4 ) respectively, were prepared. A longer time of hydrolysis for systems using CTAB as surfactant generates particles with heterogeneous chemical composition and organised areas. In fact, less organised and aluminum rich areas are distinguished by TEM analysis, especially within the biggest particles with low Si/Al molar ratio (Fig. 9). Except for the C-9.3-18 sample, these heterogeneities clearly create variations of the textural parameters and especially a bimodal pore size distribution is favoured. Interestingly, the equivalent solid of series 2 obtained by means of P123 as surfactant do not present these heterogeneities and a lower hydrolysis time of $0.17 \mathrm{~h}$ for these systems only leads to the modification of their textural parameters (Tab.2).

TABLE 2

Textural parameters obtained from $\mathrm{N}_{2}$ adsorption-desorption isotherms of series 1,2, 3 and 4 solids

\begin{tabular}{|c|c|c|c|c|c|c|}
\hline Series & Sample & $\begin{array}{c}\text { Surface } \\
\text { area } \\
\left(\mathrm{m}^{2} / \mathrm{g}\right)\end{array}$ & $\begin{array}{c}\text { Pore } \\
\text { volume } \\
\left(\mathrm{cm}^{3} / \mathrm{g}\right)\end{array}$ & \multicolumn{2}{|c|}{$\begin{array}{c}\text { Pore } \\
\text { diameter } \\
(\mathrm{nm})\end{array}$} & $\begin{array}{c}\text { Microporous } \\
\text { volume } \\
\left(\mathrm{cm}^{3} / \mathrm{g}\right)\end{array}$ \\
\hline \multirow{4}{*}{1} & C-Si-0.17 & 836 & 0.72 & \multicolumn{2}{|c|}{3.4} & 6 \\
\hline & C-9.3-0.17 & 741 & 0.58 & \multicolumn{2}{|c|}{3.1} & 0.005 \\
\hline & C-4-0.17 & 645 & 0.50 & \multicolumn{2}{|c|}{3.1} & 0.009 \\
\hline & C-1-0.17 & 556 & 0.44 & 2.3 & 8.3 & 0.02 \\
\hline \multirow{3}{*}{2} & P-9.3-18 & 276 & 0.41 & \multicolumn{2}{|c|}{7.2} & 0.006 \\
\hline & P-4-18 & 238 & 0.38 & \multicolumn{2}{|c|}{7.8} & 0.004 \\
\hline & P-1-18 & 156 & 0.26 & \multicolumn{2}{|c|}{7.8} & 0.003 \\
\hline \multirow{4}{*}{3} & C-Si-18 & 995 & 0.82 & \multicolumn{2}{|c|}{3.2} & - \\
\hline & C-9.3-18 & 832 & 0.51 & \multicolumn{2}{|c|}{2.4} & 0.022 \\
\hline & C- $4-18$ & 839 & 0.57 & $<20$ & 6.8 & 0.030 \\
\hline & C-1-18 & 482 & 0.39 & $<20$ & 6.2 & 0.022 \\
\hline 4 & P-4-0.17 & 207 & 0.32 & \multicolumn{2}{|c|}{10.3} & - \\
\hline
\end{tabular}

To understand the chemical phenomena involved in these systems, the time resolved evolution of the composition of initial solutions containing either CTAB or P123 have been 




a)

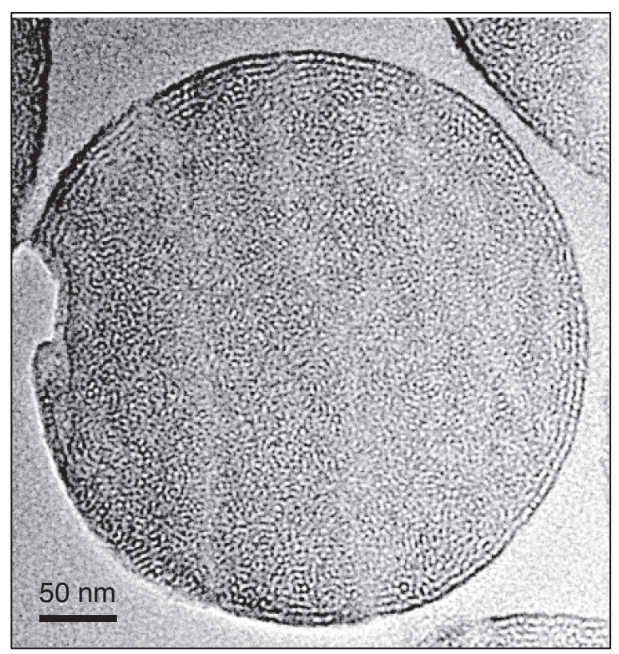

c)

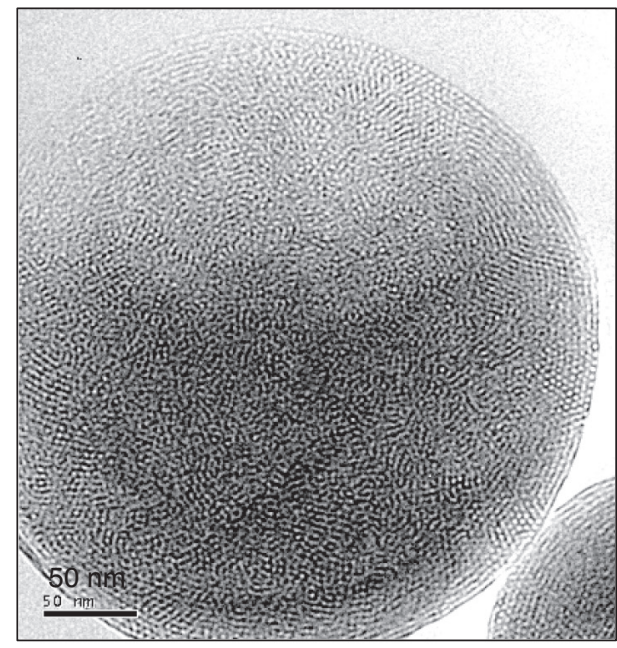

b)

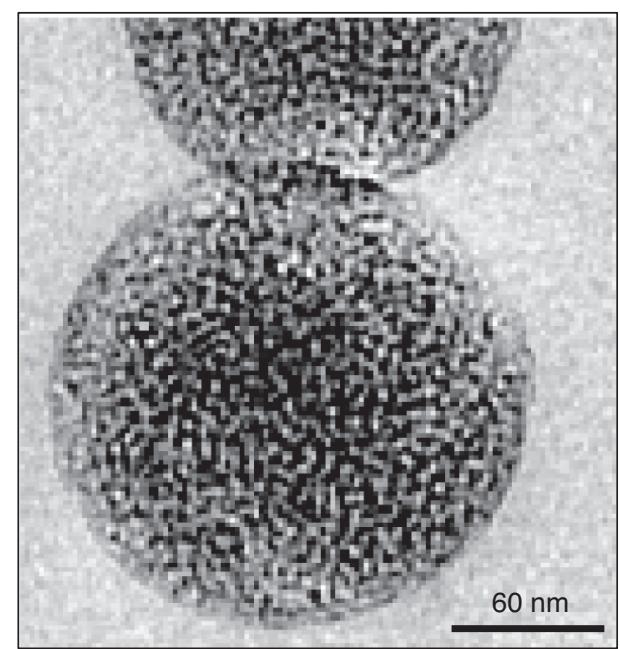

d)

Figure 3

TEM pictures obtained from of a) C-Si-0.17; b) C-9.3-0.17; c) C-4-0.17; d) C-1-0.17 microtomised samples. Series 1.

studied by $\mathrm{NMR}{ }^{27} \mathrm{Al}$ and ${ }^{29} \mathrm{Si}$ analysis. It was shown that for both systems, the formation of branched weakly condensed silica oligomers is promoted at low hydrolysis time whereas after several hours higher molecular weight molecules are logically observed. Concerning aluminum species, $\left[\mathrm{Al}\left(\mathrm{H}_{2} \mathrm{O}\right)_{6}\right]^{3+}$ and $\left[\mathrm{Al}(\mathrm{OH})\left(\mathrm{H}_{2} \mathrm{O}\right)_{5}\right]^{2+}$ with hexacoordinated aluminum are detected whatever the hydrolysis time. It is also clear that aluminum species modify the kinetics of hydrolysis and condensation reactions of silica precursors. Also, as already mentioned in an acidic media, interactions between inorganic species and surfactants are the result of electrostatic interactions between $\mathrm{M}-\mathrm{OH}_{2}{ }^{+}, \mathrm{Br}^{-}, \mathrm{N}^{+}\left(\mathrm{CH}_{2}\right)_{15} \mathrm{CH}_{3}\left(\mathrm{CH}_{3}\right)_{3}$ (with $\mathrm{M}=$ metal framework) in the case of $\mathrm{CTAB}$ and the result of hydrogen bonding between inorganic protonated species, water and EO hydrophilic groups of copolymer in the case of P123. Moreover, when the EISA process occurs within the aerosol droplets, gradients of concentration appear, leading to inorganic species diffusion toward the centre of the droplets. As a consequence, for systems using CTAB with $t=0.17 \mathrm{~h}$, the transition of the first spherical micelles into cylindrical ones, which finally leads to organic mesophases, has enough time to occur because of low condensation rate of the oxide framework. In addition, the inorganic species are small enough to have good diffusion inside the whole droplets. As a result, well organised and homogeneous particles are mostly obtained. In contrast, when $t=18 \mathrm{~h}$, the diffusion 


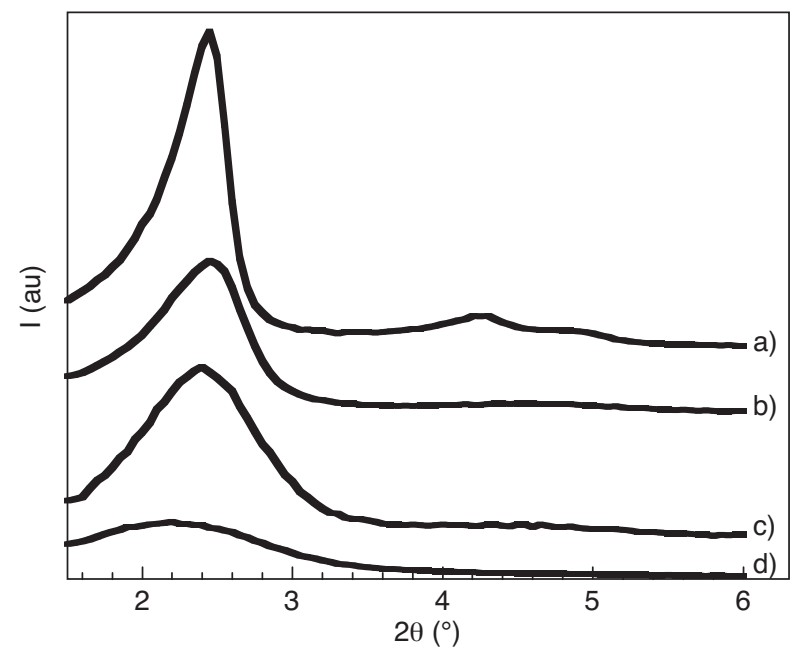

Figure 4

Low angles XRD patterns of a) C-Si-0.17; b) C-9.3-0.17; c) C-4-0.17; d) C-1-0.17 samples. Series 1 .

rates of aluminum molecular species and silica oligomers are quite different. Aluminum species move faster to the centre of the droplets and thus the corresponding particles present less organised and aluminum rich areas. For systems using P123, due to the nature of the interactions existing between inorganic species and EO groups, it is possible that aluminum molecular species are always located close to these hydrophilic groups whatever the condensation rates of silica oligomers. Moreover, as the macromolecules of copolymers are less mobile than $\mathrm{CTAB}$, the transition mechanism from the first spherical micelles to cylindrical micelles is slower. Thus, at short hydrolysis time, particles are globally homogeneous in chemical composition and less organised. As the presence of aluminum compounds in the initial solutions increases the hydrolysis and condensation reaction rates of silica precursors, all these processes of disorganisation are then magnified.

Besides, the catalytic performances of series 1,2 and 3 have been evaluated in cumene cracking reaction which involves Brönsted acid sites (see experimental section). The cumene conversions (\%) at constant solid weight and constant solid surface area as a function of $\mathrm{Si} / \mathrm{Al}$ molar ratios are shown in Figure 10. As a reference, the catalytic performance of a commercial amorphous mesoporous non-organised aluminosilicate solid (GD) [22] were also studied. First, at Si/Al molar ratios of 4 , all mesostructured solids seem to have the same catalytic behaviour as the GD sample (conversion values at constant weight are between 18 and $25 \%$ versus $12 \%$ ). This trend is even clearer if we consider the CTAB based systems at constant surface area which present conversion values quite similar to that of the GD sample (3\%). Consequently, solids from series 1 are characterised by
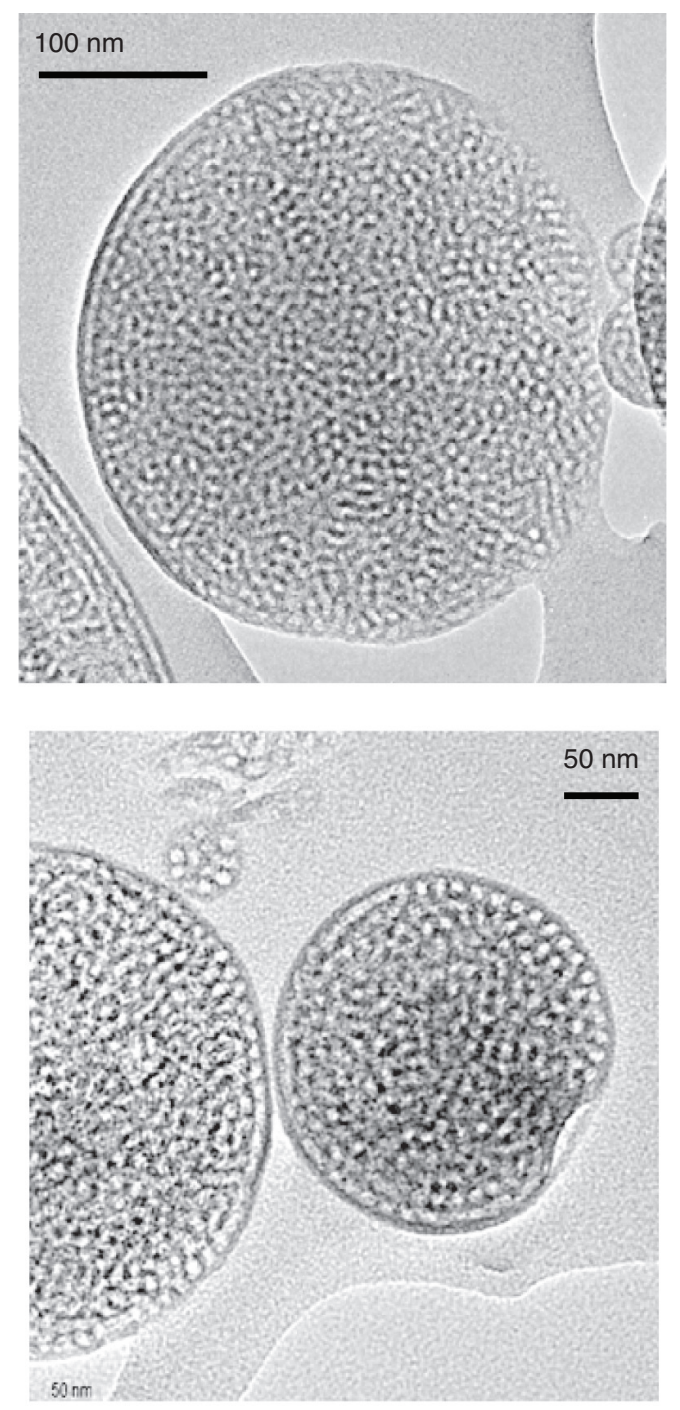

b)

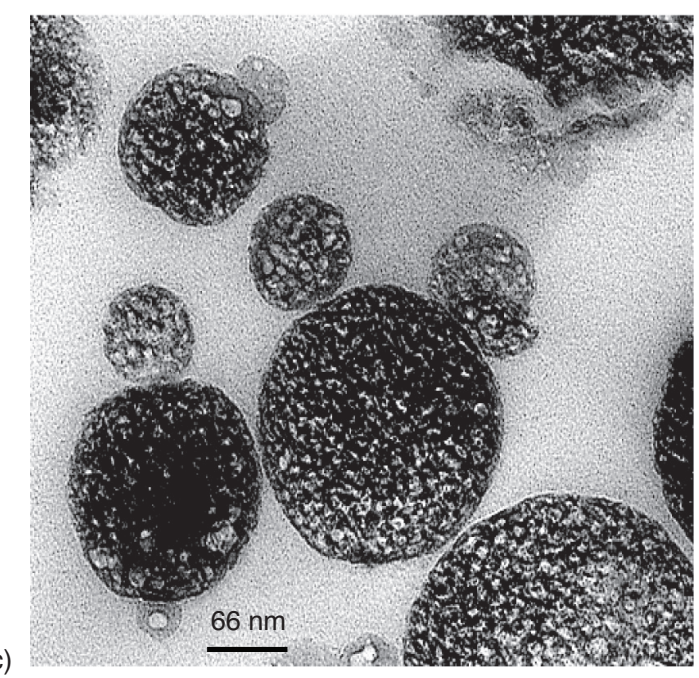

Figure 5

TEM pictures of a) P-9.3-18; b) P-4-18;

c) P-1-18 microtomised samples. Series 2 . 




Figure 6

Low angles XRD patterns of a) P-9.3-18; b) P-4-18;

c) P-1-18 samples. Series 2 .

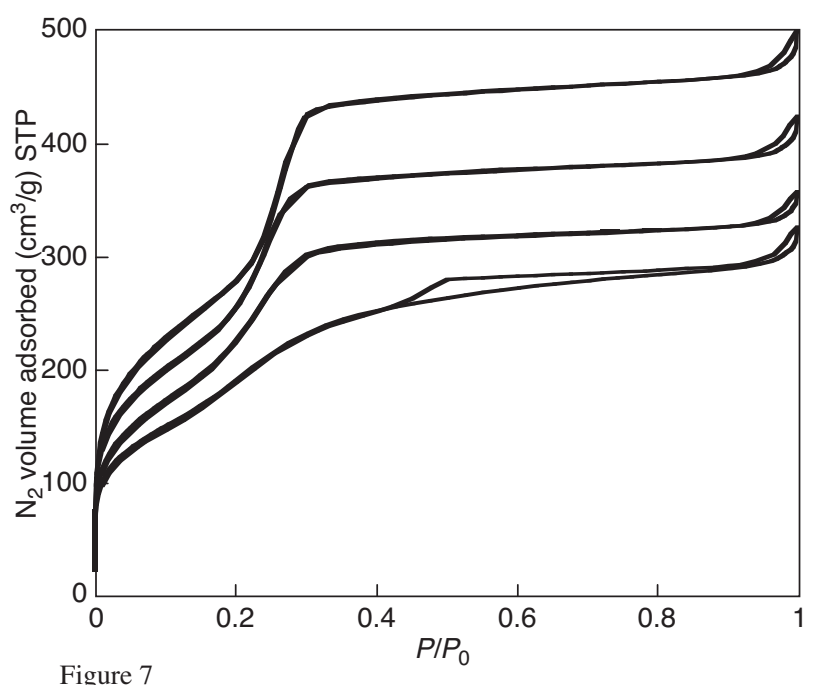

Figure 7

$\mathrm{N}_{2}$ adsorption-desorption isotherms of a) C-Si-0.17; b) C-9.30.17 ; c) C-4-0.17; d) C-1-0.17 samples. Series 1 .

Brönsted acid sites equivalent in strength and in number to those of usual amorphous mesoporous acidic solids. The few differences observed in Figure 10a are only due to small variations in the surface area values. On the contrary, the catalytic performance at constant surface area of series 2 samples are clearly better than those of all other materials with conversion values between 3.6 and $11 \%$ against 1 to $7 \%$ respectively. Active Brönsted acid sites seem to be different either in number or in strength compared to series 1, 3 and the GD sample. Additional analyses are in progress to obtain a better characterisation of these acid sites (CO adsorption followed by IR spectroscopy). Nevertheless, it can be postu-

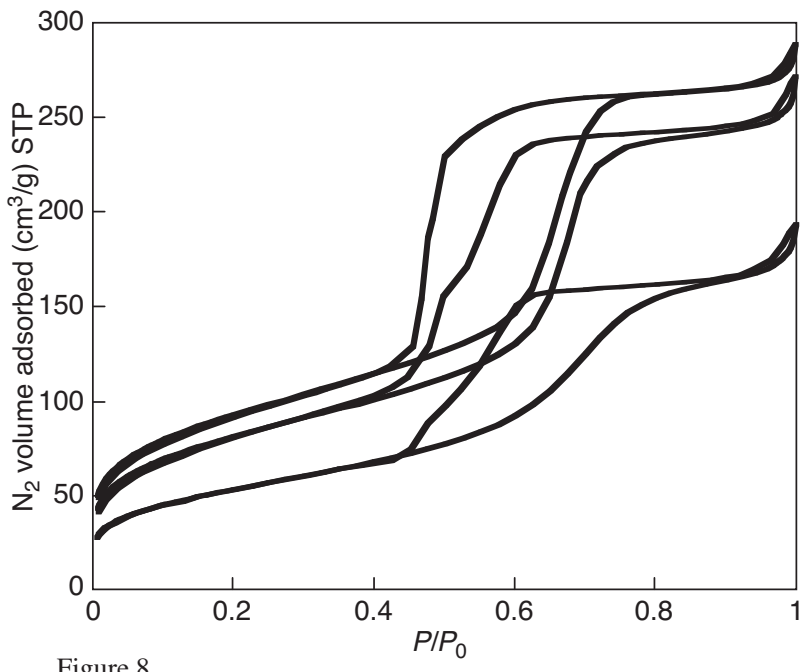

Figure 8

$\mathrm{N}_{2}$ adsorption-desorption isotherms of a) P-9.3-18; b) P-4-18; c) P-1-18 samples. Series 2 .

lated that the acid sites strength of these solids is not unusual as it is well known that mesostructured acidic materials obtained with the precursors used herein and classical mesoporous aluminosilicates present equivalent acidic properties. Moreover, even if series 2 presents high catalytic activities at constant surface area, this trend is hidden when compared at constant weight because of its lower specific area values. In all cases, the catalytic performance of these amorphous mesostructured aluminosilicate materials are significantly lower than that of a $Y$ zeolite based material $(10 \%$ weight in an alumina matrix) used as zeolitic reference, which presents conversion at constant weight around $70 \%$.

To summarise, amorphous mesotructured aluminosilicate solids with a wide range of textural parameters and high aluminum contents have been easily prepared from acidic solutions by means of the aerosol process. These results underline the great potential of the aerosol process as a new way to develop mesostructured aluminosilicate solids. However, it has been shown that the obtained solids present acidic properties similar to those of classical mesoporous non-organised aluminosilicate materials. In the following part, the acidic properties of these materials were improved by introducing zeolitic nanocrystals in the precursor solutions in order to obtain mixed "zeolite-mesostructured" nanocomposites.

\section{ZEOLITE-MESOSTRUCTURED ALUMINOSILICATE COMPOSITES OBTAINED BY THE AEROSOL PROCESS [8]}

Zeolite-mesostructured aluminosilicate composites consisting in nanocrystals of ZSM-5 zeolite embedded in an amorphous mesostructured aluminosilicate matrix have been prepared. 


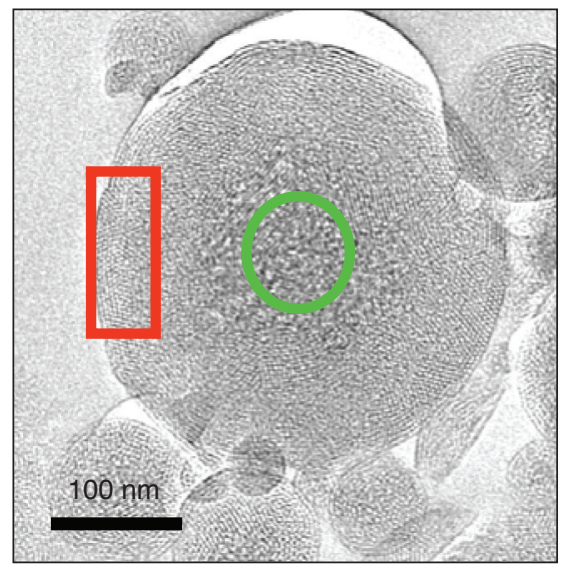

a)

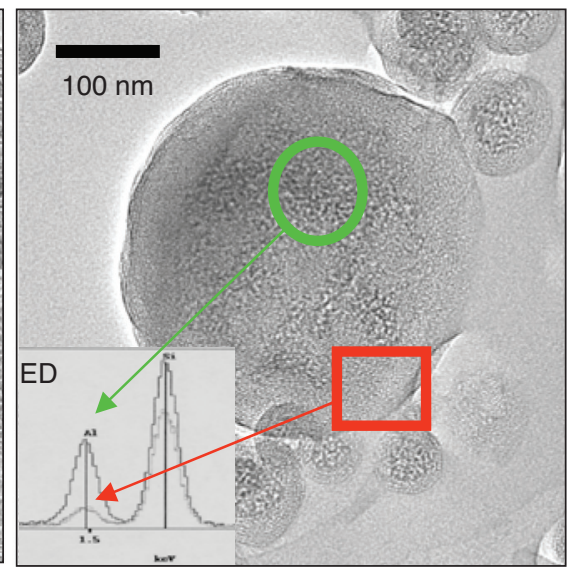

b)

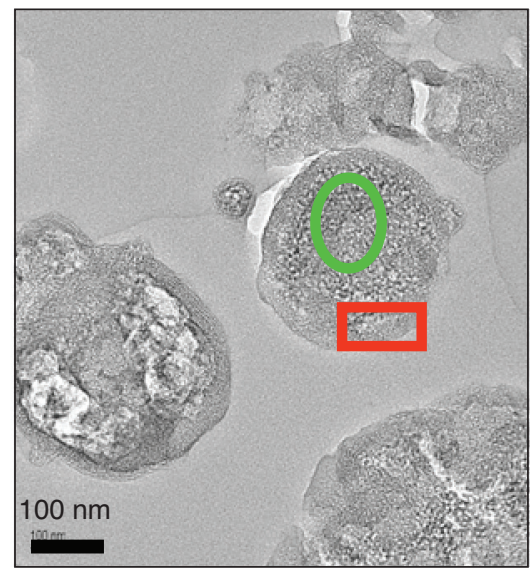

c)

Figure 9

TEM pictures of a) C-9.3-18; b) C-4-18; c) C-1-18 microtomised samples. Series 3.
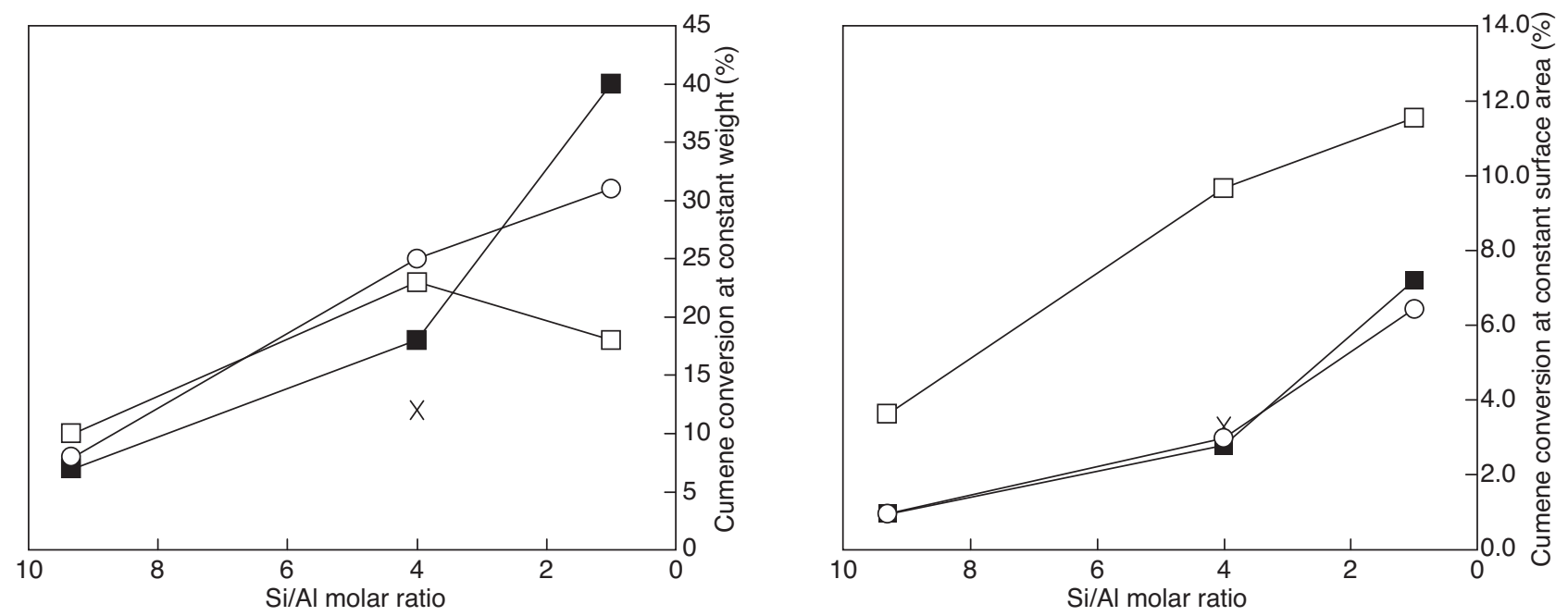

Figure 10

Catalytic performances in cumene cracking of series $1(\boldsymbol{\square}), 2(\square)$ and 3(○) and of GD sample $(\times)$ at constant weight of solid a) and constant surface area of solid b).

Experimentally, ZSM-5 (Si/Al molar ratio $=50)$ nanocrystals with $110 \mathrm{~nm}$ average in size were previously synthesized [23]. $10 \mathrm{wt} \%$ (based on the final solid weight) of these nanocrystals was added to an hydrolysed solution of precursors $(t=18 \mathrm{~h})$ with the following molar composition: $\mathrm{Si}+\mathrm{Al}, \mathrm{EtOH}, \mathrm{H}_{2} \mathrm{O}$, $\mathrm{P} 123, \mathrm{HCl}=1,30,40,0.01,0.02$, with $\mathrm{Si} / \mathrm{Al}$ molar ratio $=4$. After stirring of the resulting clear solution during $8 \mathrm{~h}$ under ultrasonic conditions, atomisation was achieved. The EISA phenomenon occurring in the heating area of the aerosol process allows the formation of the organised inorganic matrix around the preformed nanocrystals of zeolite without any disruptive effects. Nanocrystals are thus well embedded into the amorphous oxide matrix even if their incorporation is not homogeneous within all particles, possibly due to the low quantity of zeolite initially introduced (Fig. 11). Other analyses of this sample clearly correspond to data associated to both zeolite and mesostructured parts. Especially, XRD pattern is characteristic of a ZSM-5 zeolite with additional picks at low angles due to the organised amorphous matrix (Fig. 12) and $\mathrm{N}_{2}$ adsorption-desorption isotherm is a mix of types I and IV isotherms with a H1 type hysteresis cycle (not shown). The low value of the microporous volume around $0.03 \mathrm{~mL} / \mathrm{g}$ can be explained by the low quantity of initial nanocrystals of zeolite, as already mentioned (Tab.3). 


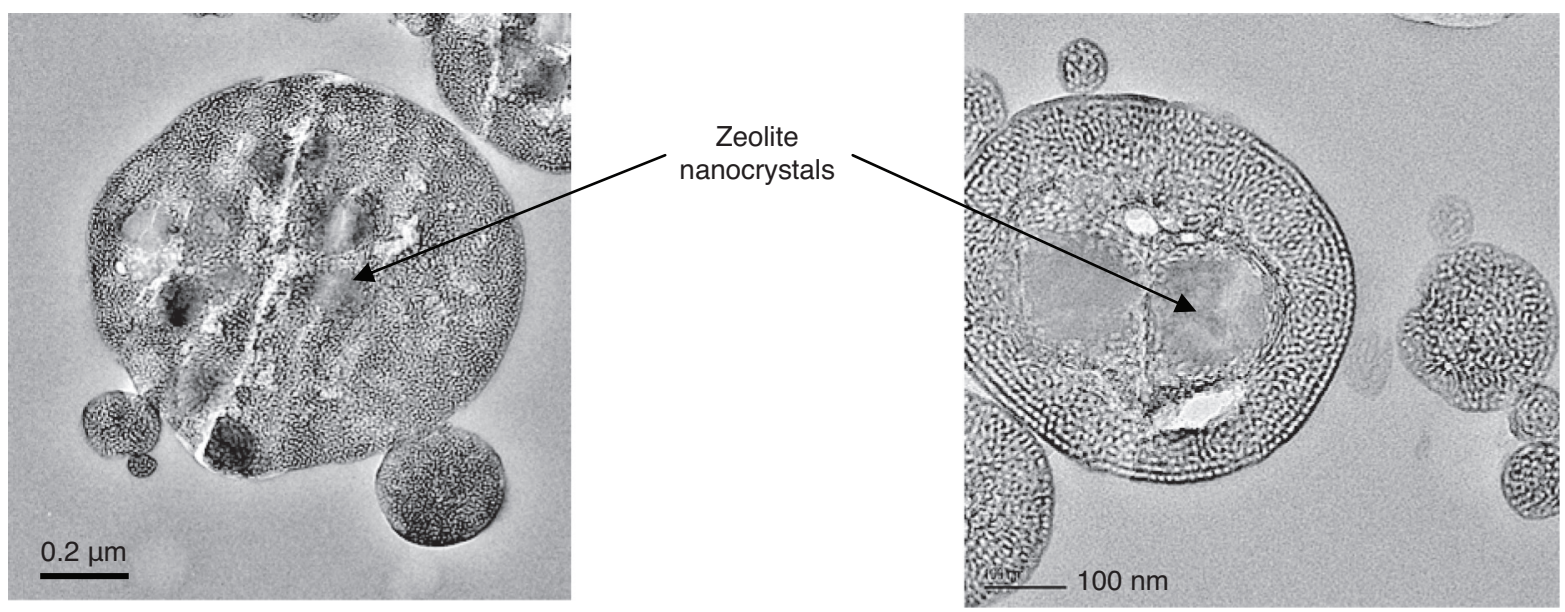

Figure 11

TEM pictures of zeolite-mesostructured aluminosilicate composite consisting in zeolite nanocrystals embedded into an amorphous mesostructuraded aluminosilicate matrix (10\% weight of ZSM-5, P123 as surfactant).
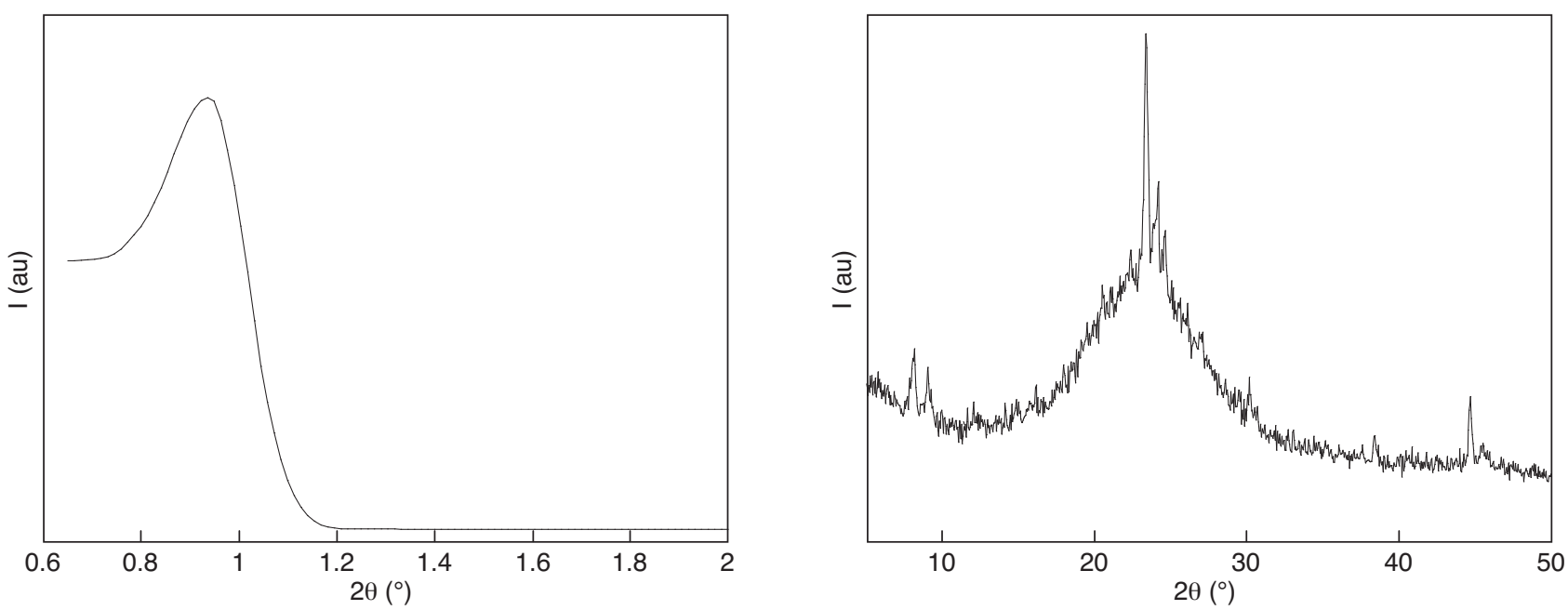

Figure 12

Low angles and high angles XRD patterns of zeolite-mesostructured aluminosilicate composite consisting in zeolite nanocrystals embedded into an amorphous mesostructured aluminosilicate matrix (10\% weight of ZSM-5, P123 as surfactant).

TABLE 3

Textural parameters obtained from $\mathrm{N}_{2}$ adsorption-desorption isotherm of zeolite-mesostructured aluminosilicate composite consisting in zeolite nanocrystals embedded into an amorphous mesostructured aluminosilicate matrix (10\% weight of ZSM-5, P123 as surfactant)

\begin{tabular}{l|c|c|c|c}
\hline \multicolumn{1}{c|}{ Sample } & $\begin{array}{c}\text { Surface } \\
\text { area } \\
\left(\mathrm{m}^{2} / \mathrm{g}\right)\end{array}$ & $\begin{array}{c}\text { Pore } \\
\text { volume } \\
\left(\mathrm{cm}^{3} / \mathrm{g}\right)\end{array}$ & $\begin{array}{c}\text { Pore } \\
\text { diameter } \\
(\mathrm{nm})\end{array}$ & $\begin{array}{c}\text { Microporous } \\
\text { volume } \\
\left(\mathrm{cm}^{3} / \mathrm{g}\right)\end{array}$ \\
\hline $\begin{array}{l}\text { Zeolite-mesostructured } \\
\begin{array}{l}\text { composite (10\% of ZSM-5, } \\
\text { P123 as surfactant) }\end{array}\end{array}$ & 320 & 0.34 & 7.4 & 0.03 \\
\hline
\end{tabular}

The acidic properties of this solid have not been evaluated yet. However, most particles present acidic, well defined amorphous mesostructured walls. Potential catalytic performance close to that of amorphous aluminosilicates can be expected from the walls, and the reactants or reaction products should be able to diffuse readily towards the zeolite nanocrystals, which could possibly act as nanoreactors where additional catalytic reactions could occur.

This example highlights real advantages of the use of the aerosol process in comparison with precipitation synthetis methods to develop new acidic solids. Indeed, in addition to 
a)

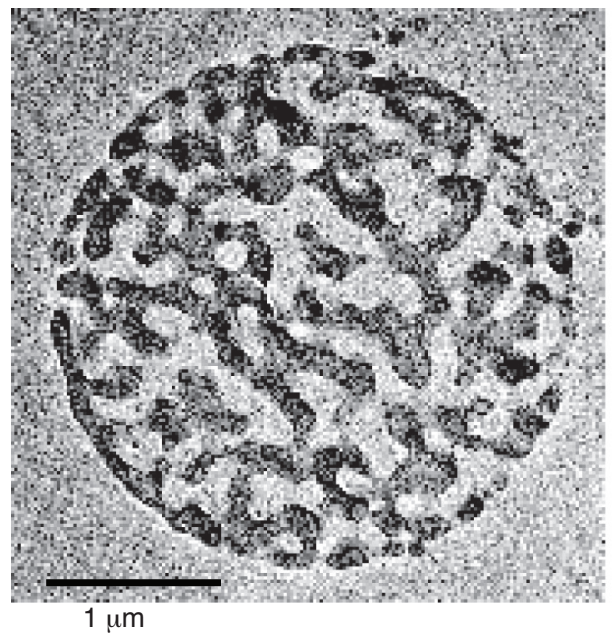

b)

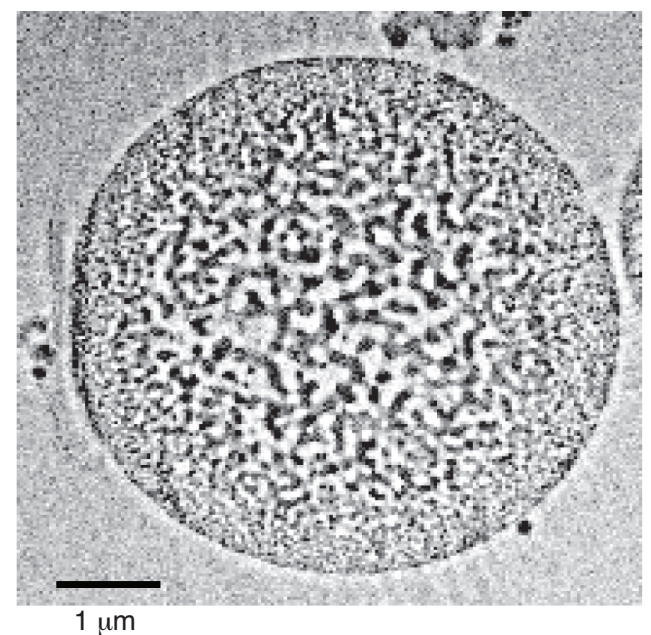

Figure 13

TEM pictures of F-50-3 sample, a) macroporous particle, b) particle with heterogeneous porous areas.

the perfect control of the chemical composition of the final solid, this process is very flexible and easy to use.

\section{NEW AMORPHOUS HIERARCHICAL ALUMINOSILICATE SOLIDS OBTAINED BY THE AEROSOL PROCESS [8]}

A preliminary study has been performed to develop new acidic mesostructured solids by the aerosol process in an alkaline media, using zeolite seeds as inorganic precursors. First, clear solutions of ZSM-5 zeolite precursors were prepared. These solutions were aged at room temperature during $18 \mathrm{~h}$. Then solutions of Pluronic F127 in water and ethanol were added. The final molar compositions studied are the following: $\mathrm{Si}+\mathrm{Al}$, EtOH, $\mathrm{H}_{2} \mathrm{O}, \mathrm{F} 127$, TPAOH, $\mathrm{NaOH}=1, x, y$, $5.10^{-3}, z, 8.10^{-3}$, with $17 \leq x \leq 30,40 \leq y \leq 57,21 \leq z \leq 23$. ${ }^{27} \mathrm{Al}$ NMR analysis of the solutions before atomisation shows that only tetracoordinated aluminum species are detected. The aluminum species are probably small anionic aluminosilicate oligomers as proposed in the literature for equivalent stable solutions containing TPAOH, silicate and aluminate species [24]. Hydrolysed and condensed oligomers are hence different from those involved in the synthesis of solids of series 1 to 4 previously discussed. Four samples with various $\mathrm{Si} / \mathrm{Al}$ and $\mathrm{H}_{2} \mathrm{O} / \mathrm{EtOH}$ molar ratios were obtained after the spray-drying process (series 5 ). For example, the sample synthesised with $\mathrm{Si} / \mathrm{Al}=10$ and $\mathrm{H}_{2} \mathrm{O} / \mathrm{EtOH}=1.3$ is called F-10-1.3. Because of the presence of $\mathrm{Na}^{+}$cations in the atomisation solutions, the F-10-1.3 and F-50-1.3 samples were washed with $\mathrm{NH}_{4} \mathrm{NO}_{3}$ solution after the calcination step and were further submitted to another subsequent thermal treatment (drying and calcination) in order to reveal Brönsted type acidic properties. These samples are identified by the "L" letter at the end of the above nomenclature. As previously discussed, the expected aluminum contents are obtained thanks to the EISA process and no significant sodium content was detected after $\mathrm{NH}_{4} \mathrm{NO}_{3}$ washing (not shown). The morphological and textural analyses show that solids of series 5 do not present any organisation but a hierarchical non-organised porosity due to interconnected inorganic areas. These particular textures are due to a spinodal decomposition mechanism occurring during the EISA process, probably thermodynamically favoured in our operating

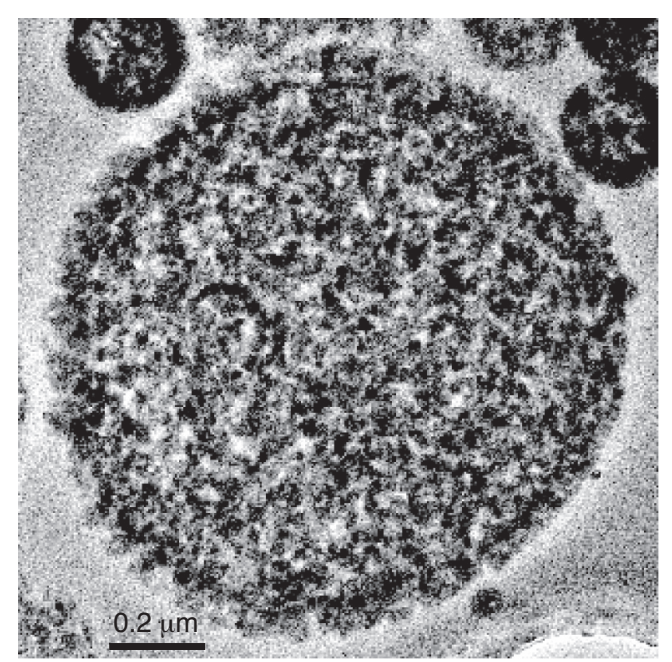

Figure 14

TEM pictures of F-10-1.3 sample. 

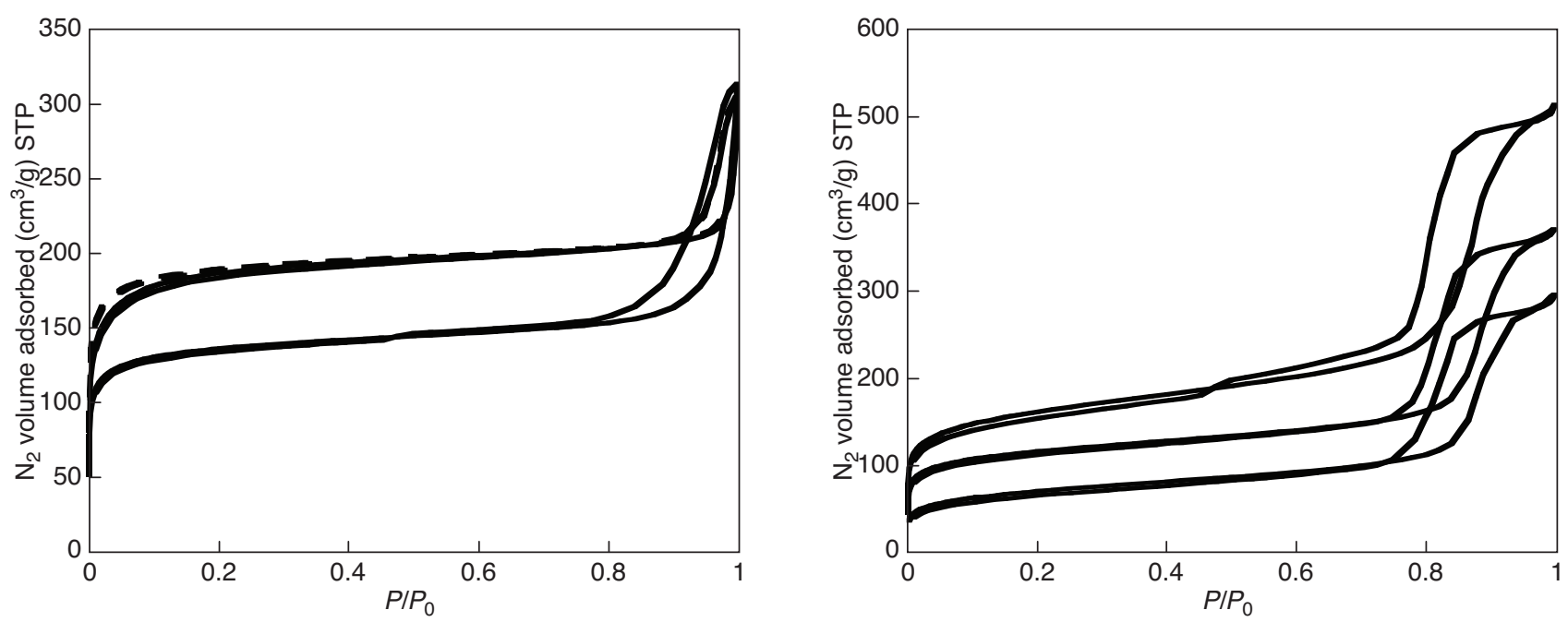

Figure 15

$\mathrm{N}_{2}$ adsorption-desorption isotherms of a) F-50-3, b) F-50-1.3, c) F-50-1.3-L, a') F-10-3, b') F-10-1.3 and c') F-10-1.3-L samples. Series 5.

conditions towards self-assembly mechanism. Morphologies observed only depend on the aluminum content. With a high $\mathrm{Si} / \mathrm{Al}$ molar ratio, two types of particles are visible: in a first class, particles present macroporous domains with homogeneous size between 50 and $500 \mathrm{~nm}$. In a second class, particles are heterogeneous with macroporous domains at the centre and pore size that progressively decreases when approaching the periphery to finally form mesoporous areas (Fig. 13). For lower values of Si/Al molar ratio, only homogeneous and mesoporous particles with a size distribution between 15 and $25 \mathrm{~nm}$ are obtained (Fig. 14). Moreover, even if zeolite seeds solutions are used herein, all series 5 samples are amorphous (no zeolite diffraction peak on the corresponding XRD patterns). Significant microporosity was however detected, probably due to the presence of TPAOH as microporous directing agent (Tab. 4). In fact, $\mathrm{N}_{2}$ adsorptiondesorption isotherms are all characteristic of microporous

TABLE 4

Textural parameters obtained from $\mathrm{N}_{2}$ adsorption-desorption isotherms of F-50-3, F-50-1.3, F-50-1.3-L, F-10-3, F-10-1.3 and F-10-1.3-L samples. Series 5

\begin{tabular}{c|c|c|c|c|c}
\hline & Sample & $\begin{array}{c}\text { Surface } \\
\text { area } \\
\left(\mathrm{m}^{2} / \mathrm{g}\right)\end{array}$ & $\begin{array}{c}\text { Pore } \\
\text { volume } \\
\left(\mathrm{cm}^{3} / \mathrm{g}\right)\end{array}$ & $\begin{array}{c}\text { Pore } \\
\text { diameter } \\
(\mathrm{nm})\end{array}$ & $\begin{array}{c}\text { Microporous } \\
\text { volume } \\
\left(\mathrm{cm}^{3} / \mathrm{g}\right)\end{array}$ \\
\hline \multirow{4}{*}{ Series 5 } & F-50-3 & 614 & 0.47 & $>300$ & 0.28 \\
\cline { 2 - 6 } & F-50-1.3 & 582 & 0.47 & $>300$ & 0.28 \\
\cline { 2 - 6 } & F-50-1.3-L & 431 & 0.44 & $>300$ & 0.29 \\
\cline { 2 - 6 } & F-10-3 & 489 & 0.80 & 196 & 0.13 \\
\cline { 2 - 6 } & F-10-1.3 & 356 & 0.61 & 196 & 0.11 \\
\cline { 2 - 6 } & F-10-1.3-L & 207 & 0.47 & 182 & 0.04 \\
\hline
\end{tabular}

samples with an additional hysteresis cycle at high $P / P_{0}$ values, induced by meso and macroporous areas described above (Fig. 15). Notice that when a washing step is performed, the microporous volume decreases when the aluminum content increases.

In addition to the classical analyses mentioned above, the F-50-3 sample was characterised by specific 3D-TEM analyse (three-dimensional Transmission Electron Microscopy) which consists in the volume reconstruction of an object from a series of projections recorded by turning the sample inside an electron microscope [25]. Its main advantage is the capability to yield information of volumetric character on complex objects. Especially, in our case, 3D-TEM can give information about the porosity of our solid: type of connexions between the pores, pores extended through the entire particle or not, accessibility of the pores by reagents, etc. Moreover, the shape, the volume and the specific area can also be quantified. Applying 3D-TEM technique to the F-50-3 sample and modelling its reconstructed volume (Fig. 16), it has been shown that all pores are totally interconnected and extend outside the particles. In addition, the study of two different objects (elementary particles) has led to a mean macroporous volume of $0.27 \mathrm{~mL} / \mathrm{g}$ which can be compared to $\mathrm{N}_{2}$ adsorption-desorption value of $0.19 \mathrm{~mL} / \mathrm{g}$. The specific surface area of the macroporosity is estimated to $30 \mathrm{~m}^{2} / \mathrm{g}$ which also compares well to the macroporous specific area of $31 \mathrm{~m}^{2} / \mathrm{g}$ measured by $\mathrm{N}_{2}$ adsorption-desorption isotherm coupled to mercury porosimetry (not shown). 3D TEM also gives an estimation of the size of the pores mouths, about 40 to $60 \mathrm{~nm}$, the size of the pores about $80 \mathrm{~nm}$, and the size of the entanglements, which are in all cases larger than 10 to $20 \mathrm{~nm}$. These values are large enough to allow cumene and much 


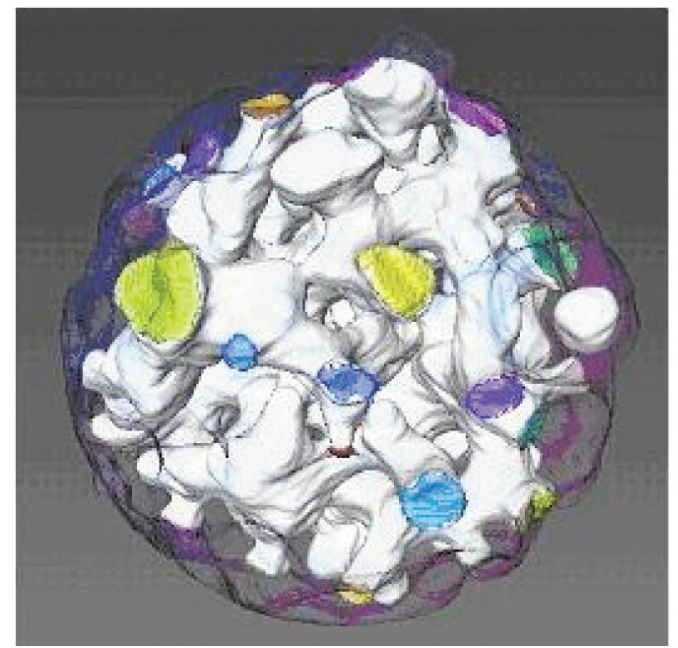

Figure 16

3D-TEM segmentation of a particle of F-50-3 sample (transparent purple) and of its porosity (white). The pore mouths are visualised by different colours.

larger molecules to diffuse easily inside this material. We have also developed a routine to measure the tortuosity of the pores and the distance map from one pore mouth to another, depending of the size of the molecule. The tortuosity corresponds to the ratio of the distance between two mouths as seen by the molecule (geodesic distance) by the bird's eye distance (Euclidian distance). A tortuosity of 1 corresponds to a straight course. The distance map gives an idea of the course of a molecule of a given size. Figure 17 illustrates two examples of distance map for molecule sizes of 6.7 and $13.4 \mathrm{~nm}$ (Fig. 17a) and a graph which presents the percentage of interconnected pores, in function of the size of the molecule (Fig. 17b). For cumene, $100 \%$ of the pores are interconnected.

To induce a mesostructuration process, hydrolysis and condensation reactions of inorganic precursors as well as organic micelles assembly have to occur simultaneously. This means that kinetic variations of these reactions could easily disturb the EISA process and induce phase segregation by spinodal decomposition mechanism. Moreover, strong and stable interactions between organic and inorganic phases must be favoured. In alkaline media, assumed aluminosilicate oligomers are negatively charged and hence could interact by repulsive electrostatic interactions with the hydrophilic EO groups which also bear a significant negative partial charge. In addition, hydrolysis and condensation rates of these inorganic precursors are slower than in an acidic media. Consequently, as the inorganic phase condenses, phase segregation occurs. Moreover, the addition of various aluminum contents increases kinetic disruptions and modifies phase interactions, leading to a very complex system. Nevertheless, it has been shown that distinct studies on the impact of various $\mathrm{OH}^{-}$, $\mathrm{TPA}^{+}$(probably playing a crucial role at the inorganic organic interface) and $\mathrm{Al}$ contents, allow to define operating areas where EISA process is favoured (to be submitted).

Even if solids of series 5 are not mesostructured, their well interconnected porosity at meso and macroporous scales can be interesting for catalytic cracking applications, especially to treat heavy petroleum fractions. That is why acidic properties were also evaluated by means of cumene cracking reaction (Fig. 18). First, high aluminum contents induce better catalytic performances whatever the samples. Eventhough the

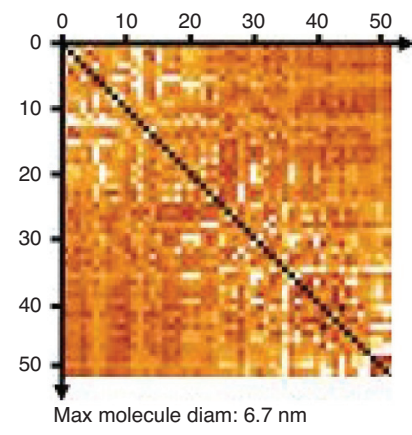

a)

Figure 17

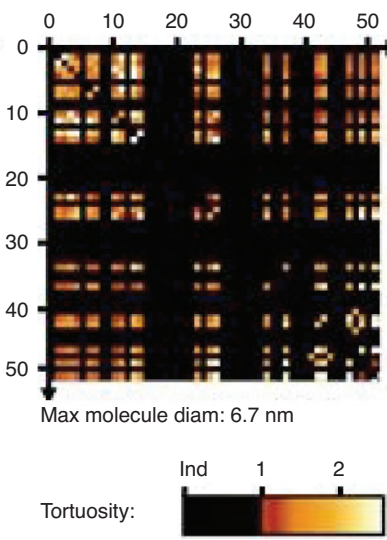$$
\text { b) }
$$

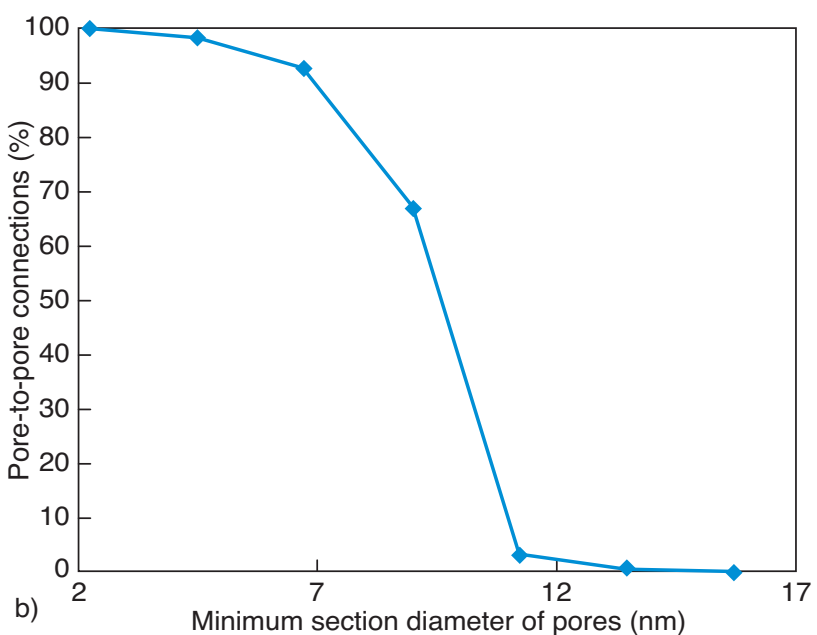

a) Distance maps for two molecule sizes $(6.7$ and $13.4 \mathrm{~nm})$ and b) percentage of interconnections of the pores, depending of the diameter of the pores obtained by 3D-TEM analysis of F-50-3 sample. 

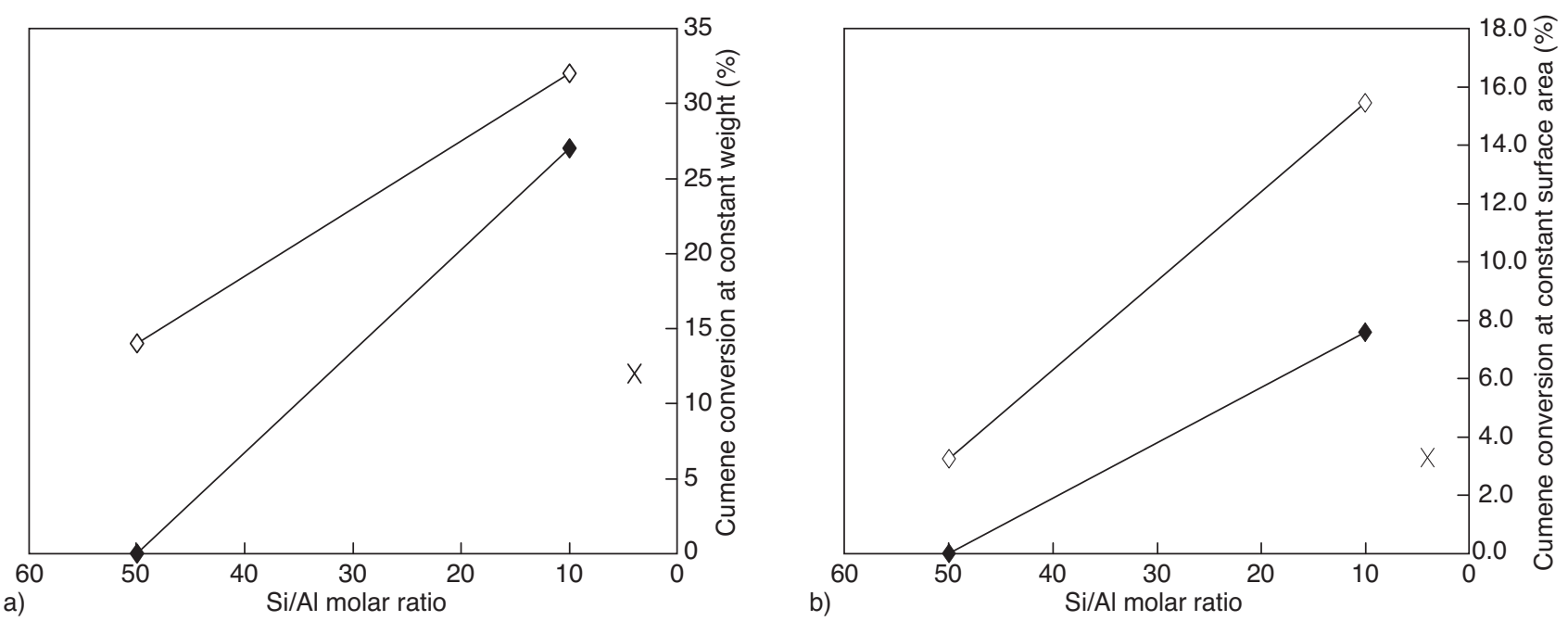

Figure 18

Catalytic performances in cumene cracking of a) F-50-1.3 and F-10-1.3 samples ( $\bullet)$, b) F-50-1.3-L and F-10-1.3-L samples ( $)$ ).

washing step damages the inorganic walls, this non optimised process allows the formation of Brönsted acid sites. F-10-1.3 and especially F-10-1.3-L samples compared with C-9.3-18, C-9.3-0.17, P-9.3-18 and GD samples are clearly more active either at constant weight or at constant surface area. At the time of writing, these results are difficult to explain, all the more since $\mathrm{CO}$ adsorption followed by infrared and ${ }^{27} \mathrm{Al}$ NMR analyses of C-4-0.17 and F-10-1.3 samples have not shown significant differences in nature and strength of their acidic sites.

To sum up, amorphous aluminosilicate materials with hierarchical porosity from micro to macroporosity have been synthesized by means of the aerosol process. Even if no structuration of the porosity has occurred, the well opened inorganic matrix obtained and the catalytic performances reached in cumene cracking reaction for a $\mathrm{Si} / \mathrm{Al}$ molar ratio of 10 underline the potential interest of this kind of solids for cracking and hydrocracking applications. These results are probably the first step towards new mesostructured aluminosilicate materials with breakthrough acidic properties compared to those of usual non organised mesoporous acidic solids.

\section{CONCLUSIONS}

The aerosol process is a very suitable, versatile and flexible process which allows the continuous production of oxide materials with limited operating steps. Especially the aerosol process, by means of the EISA chemical phenomenon, successfully lead to mesostructured or hierarchical porous solids, providing accurate control of the experimental parameters was achieved (polarity and evaporation rate of solvents, evaporation temperature, organic surfactants nature, etc.). Consequently and for the first time, several families of amorphous aluminosilicate materials were synthesised by this process. Because of the spray-drying process used, the materials synthesised consist in elementary spherical particles obtained at nanometric scale with a well opened porosity which is either organised and uniform at the mesoporous scale or hierarchical from microporosity to macroporosity. Moreover, all solids are characterised by a wide range of aluminum contents. In addition, zeolite nanocrystals could be easily incorporated in the previous aluminosilicate solids, leading to an additional lever to target specific acidic properties. The preliminary catalytic results in cumene cracking reaction shown herein underline the great potential of these solids as new acidic supports for industrial applications. However, their hydrothermal stability and their catalytic performances with large molecules are key points that are still under study. Furthermore, a better understanding of the impact of each operating parameters of the spray-drying process could allow an increase in the number of new solids potentially achievable.

\section{REFERENCES}

1 AIE World Energy Outlook (2006).

2 Marcilly C. (2003) Catalyse acido-basique. Application au raffinage et à la pétrochimie, Vol. 2, Technip Ed., Paris.

3 Beck J.S., Vartuli J.C., Roth W.J., Leoniwicz M.E., Kresge C.T., Schmitt K.D., Chu C.T.-W., Olson D.H., Sheppard E.W., McCullen S.B., Higgins J.B., Schlenker J.L. (1992) J. Am. Chem. Soc. 114, 10834.

4 Soler-Illia G.J. de A.A., Sanchez C., Lebeau B., Patarin J. (2002) Chem. Rev. 102, 4093. 
5 Zhao D.Y., Feng J.L., Huo Q.S., Melosh N., Fredrickson G.H., Chmelka B.F., Stucky G.D. (1998) Science 279, 548.

6 Yue Y.-H., Gedeon A., Bonardet A., d'Espinose J.-L., Melosh J.B., Fraissard N. (2000) Stud. Surf. Sci. Catal. 129, 209.

7 Coupé A. (2005) Développement et caractérisation de matériaux fonctionnels à base d'aluminosilicates micro et mésoporeux : application à la catalyse acide, Thèse, Université Pierre et Marie Curie, Paris.

8 Prokesova L., Mintova S., Cejka J., Bein T. (2003) Mat. Sci. Eng. C-Bio.S. 23, 1001; Zhang Z., Han Y., Xiao F.-S., Qiu S., Zhu L., Wang R., Yu Y., Zhang Z., Zou B., Wang Y., Sun H., Zhao D., Wei Y. (2001) J. Am. Chem. Soc. 123, 5014; Liu Y., Pinnavaia T.J. (2002) J. Mater. Chem. 12, 3179; Triantafyllidis K.S., Iliopoulou E.F., Antonakou E.V., Lappas A.A., Wang H., Pinnavaia T.J. (2007) Micropor. Mesopor. Mat. 99, 132.

9 Xu W., Dong J., Li J., Wu F. (19990) Chem. Commun. 755; Naik S.P., Chiang A.S.T., Thompson R.W., Huang F.C. (2003) Chem. Mater. 15, 787; Ogura M., Zhang Y., Elangovan S.P., Okubo T. (2007) Micropor. Mesopor. Mat. 101, 224.

10 Cagnol F., Grosso D., Soler-Illia G.J. de A.A., Crepaldi E., Babonneau F., Amenitsch H., Sanchez C. (2003) J. Mater. Chem. 13, 61; Brinker C.J., Fan H. (2004) Stud. Surf. Sci. Catal. 148, 213; Grosso D., Babonneau F., Albouy P.-A., Amenitsch H., Balkenende A.R., Brunet-Bruneau A., Rivory J. (2002) Chem. Mater. 14, 931; Grosso D., Balkenende A.R., Albouy P.A., Ayra A., Amenitsch H., Babonneau F. (2001) Chem. Mater. 13, 1848; Grosso D., Soler-Illia G.J. de A.A., Crepaldi E.L., Charleux B., Sanchez C. (2003) Adv. Funct. Mater. 13, 37; Sanchez C., Boissière C., Grosso D., Laberty C., Nicole L. (2008) Chem. Mater. 20, 682.

11 Boissiere C., Grosso D., Amenitsch H., Gibaud A., Coupé A., Baccile N., Sanchez C. (2003) Chem. Commun. 22, 2798.

12 Brinker C.J., Lu Y., Sellinger A., Fan H. (1999) Adv. Mater. 11, 7,579 .

13 Zhao D., Yang P., Margolese D., Stucky G.D. (1998) Chem. Commun. 2499; Grosso D., Balkenende A.R., Albouy P.A., Lavergne M., Mazerolles L., Babonneau F. (2000) J. Mater. Chem. 10, 2085; Honma I., Zhou H.S., Kundu D., Endo A. (2000) Adv. Mater. 12, 1529; Sanchez C., Boissière C., Grosso D., Laberty C., Nicole L. (2008) Chem. Mater. 20, 682.
14 Baccile N., Grosso D., Sanchez C. (2003) J. Mater. Chem. 13, 3011; Alonso B., Vrain A., Beaubois E., Massiot D. (2005) Progress in Solid State Chemistry - Advanced Functional Nanomaterials - from NanoscaleObjects to Nanostructered Inorganic and Hybrid Materials, 33, 153; Boissiere C., Nicole L., Gervais C., Babonneau F., Antonietti M., Amenitsch H., Sanchez C., Grosso D. (2006) Chem. Mater. 18, 5238.

15 Nakanishi K. (1997) J. Porous Mat. 4, 67.

16 Bore M.T., Marzke R.F., Ward T.L., Datye A.K. (2005) J. Mater. Chem. 15, 5022; Pega S., Coupe A., Boissiere C., Azais T., Grosso D., Sanchez C., Blanchard J., Massiot D., Chaumonnot A. (2008) Nanoporous materials, Vancouver, Canada, p. 457.

17 Broekhoff J.C.P., De Boer J.H. (1968) J. Catal. 10, 377.

18 Barret E.P., Joyner J.G., Halenda P.P. (1951) J. Am. Chem. Soc. 73, 373 .

19 Jaroniec M., Kruk M., Olivier J.P. (1999) Langmuir 15, 5410.

20 Biz S., White M.G. (1999) J. Phys. Chem. B 103, 8432.

21 Mokaya R. (2000) J. Phys Chem. B 104, 8279; Chatterjee M. (1998) Catal. Lett. 52, 21.

22 Zeng S. (2005) PhD thesis, Université Pierre et Marie Curie, Paris.

23 Tosheva L., Valtchev V.P. (2005) Chem. Mater. 17, 2494.

24 Swaddle T.W., Salerno J., Tregloan A. (1994) Chem. Soc. Rev. 321; Mortlock R.F., Bell A.T., Radke C.J. (1991) J. Phys. Chem . 95, 372; Kinrade S.D., Swaddle T.W. (1989) Inorg. Chem. 28, 1952.

25 Ersen O., Hirlimann C., Drillon M., Werkmann J., Tihay F., Pham-Huu C., Crucifix C., Schultz P. (2007) Solid State Sci.9, 1088.

Final manuscript received in May 2009 Published online in September 2009 or distributed for profit or commercial advantage and that copies bear this notice and the full citation on the first page. Copyrights for components of this work owned by others than IFP must be honored. Abstracting with credit is permitted. To copy otherwise, to republish, to post on servers, or to redistribute to lists, requires prior specific permission and/or a fee: Request permission from Documentation, Institut français du pétrole, fax. +33147527078 , or revueogst@ifp.fr. 